\title{
Role of Television in Making Polio-Free India
}

\author{
SANTOSH K. GAUTAM
}

\begin{abstract}
This study aimed to find a popular medium of mass communication that played the most significant role in polio eradication. The research paper was based on the concept of health communication, which is an integral part of development communication. Mass media, especially television, is the most powerful and effective medium of mass communication and a very important tool for shaping the Indian society. It can inform, educate, and motivate people to perform any desired behavior. This study explored that awareness level of people on health issues was very high. Most of the respondents claimed, they had been watching advertisements pertaining to social issues on television. It was also revealed that the level of participation of people in polio eradication was very high, i.e., 96 percent respondents reported that they went to the polio booth after watching the polio advertisement on television which was advocated by celebrities like Amitabh Bachchan, Shahrukh Khan, Jaya Bachchan, Sachin Tendulkar, Aishwarya Rai and many more. Thus, this study also showed that TV as a mass medium for health communication was a very effective tool and it could also be argued that television had played a significant role in making polio-free India. While planning the present research, it was felt that an attempt should be made to provide a complete picture of the role of communication in semi-urban society of Lucknow district with specific reference to polio eradication.
\end{abstract}

Key words: Health communication, Television, Polio eradication, Mass campaign, Awareness, Mass media and Advertisement

India's polio eradication awareness campaign tells inspiring story for many nations which are struggling to overcome from this health hazard due to poor Medicare facilities. On 13 January 2013, UNICEF announced that India had completed two years without any reported case of polio. The last case was known when a two-yearold girl was diagnosed with polio in Howrah district of West Bengal on 13 January 2011. India achieved a major milestone with the World Health Organization (WHO) striking it off the list of polio endemic countries on 25 February 2012 (UNICEF, 2012). WHO recorded 23,800 cases of polio between 1988 and 13 January 2011 in India (Sachffer, 2012, p.1-18). Through polio eradication efforts, a significant investment had been made in strengthening health service delivery systems in many countries. An estimated 10 million health workers and volunteers have been engaged in implementing the necessary polio supplementary immunization activities (SIAs) on a recurring basis and at least 35,000 well-trained workers had been conducting polio surveillance (Goswami, 2007, p.381). Polio eradication campaign is a joint effort of the Ministry of Health and Family Welfare, UNICEF, the administration, and mass media to make India polio free. India formally adopted a lot of the media campaigns strategy as well as interpersonal communication strategy to eradicate polio.

Today mass media in all its forms (television, radio, newspaper, social media and cinema) are effectively transmitting messages of polio awareness and eradication. The reach (penetration) and availability of mass media plays a very important role in spreading awareness about polio 
eradication (Kulkarni, 1992). In order to address challenges in health intervention, television can play very prominent role in the field of healthcare and work towards the betterment of human life. Communication interventions using mass media can be a powerful tool for raising awareness, encouraging people towards recommended behavioural changes and restricting spread of disease. Television can disseminate information as regards different health issues and have effect on human behaviour as well. Television asserts through its informative function to influence beliefs, attitudes and values which influences people to do away with outmoded perception or cognitive dissonance so that they could adopt modern and scientific technologies, ideas etc. In the process of health promotion, the access and availability of television is important for betterment of socio-economic status, health education, and also for participation of masses in the process of development.

\section{Health communication:}

According to Rogers (1995) "Health communication is any type of human communication whose content is concerned with health" (p.344). It is a vital component of every form of medicine and healthcare, i.e., it plays an important role to educate and make community and its people aware to guard against severe diseases. Health communication is a subset of communication that concerns itself about how an individual in a society seeks to maintain health and deal with health related issues, that is, how health related messages are shaped, disseminated, accessed and interpreted. Development planners use different mass media vehicles to spread health related messages to influence attitude and behaviour of members of a society and persuade them to act towards the desired direction. Health communication is also concerned with communication among policy makers, health planners, doctors, patients and community in health realm. It is an emerging field in which professional communicators and health providers inform, influence and motivate an individual, institutional, governmental, and public audience about important health issues (Yzer, 2009, p.3031). Social and behavioural scientist Schiavo (2007) defines:

"Health communication is a multifaceted and multidisciplinary approach to reach different audiences and share health related information with the goal of influencing, engaging and supporting individual, communities, health professionals, special groups, policy makers and the public to introduce, adopt or sustain a behaviour, practice or policy that will ultimately improve health outcomes".

\section{Pulse polio campaign in India}

In 1988, WHA resolution calling for global polio eradication, wild polio virus was endemic in more than 125 countries on five continents, paralyzing more than 1000 children every day (John, 1984; 2006). As of May 2005, polio myelitis occurs primarily in Africa and South Asia. In 1995-96 India scheduled two national immunization day and the first phase of immunization covered children of up to 3 years of age (Bhattacharjee et al., 1997), later it expanded up to 5 years (Goswami, 2007, p.372).

In the beginning, pulse polio immunization gained enormous popularity as a peoples' welfare program, unleashed an immense spirit of volunteerism that brought the prevention of a communicable disease beyond the realm of public health. Large numbers of volunteers, including teachers, students, religious leaders, medical practitioners, community leaders, homemakers, came forward with the program's inception in December 1995. They operated over 700,000 vaccination booths, talked to families, made public appeals and organized students' rallies. Throughout the country, school children took to the streets in droves to raise awareness of National Immunization Day (Weiss et al., 2011, p.2-4). 
Mass media along with traditional media was used to mobilize rural people. Villagers pedaled loudspeakers around while rows of young people marched to the rhythmic beat of drums, publicizing the day with much fanfare and colour. The eradication team mobilized state health machinery across the country. Two million volunteers reached 87 million children up to age five. Setting up a surveillance system, another important arm of polio eradication was media who gave speed to the campaign. In 1997 Danish aid agency and DANIDA made an 11.5 million support to surveillance the campaign. Polio cases reported in India were 23800 from 1994 to 2010 (Sachffer, 2012, p.7).

\section{Mass campaign against polio}

The high level of polio vaccination coverage indicates that over 90 percent of the population had been aware of polio eradication. Ministry of health and family welfare has popularized polio eradication campaign engaging well-known personalities of different fields such as politician, film star and sports stars etc. Popular and wellknown famous personalities regularly appeared on national television. They appealed to masses by using the short and simple catchy tagline "Do boond zindagi ke" (two drops of life). Polio drops were a well-known product to protect children from disability limbs.

In 1999-2000 UNICEF proposed a national media campaign of polio eradication. Thereafter, the mass media campaign focused on social and emotional appeal that aimed to motivate parents to bring children to polio booths for vaccination. A professional aid agency Ogilvie and Mather was hired to develop pulse polio eradication messages (UNICEF, 2003, p. 24). Ogilvie designed content engaged with emotional and local approaches.

\section{Strategies adopted to make polio free India}

The aim of communication and social mobilization strategies prior to 2013 was to create awareness of pulse polio and later it was focused on to bring parents repeatedly onto polio booth to eradicate polio from the root. The challenge confronting the government, UNICEF and the Social Mobilization Working Group (SMWG) was two-fold. First, how to disseminate information to the unreached underserved communities? And how to tackle resistance to Oral Polio Vaccine (OPV) vaccination? Second, how to motivate the majority of people for next two years for vaccination that already participated in OPV. Although, the efforts of polio eradication in India faced challenges when a 2003 Fatwa issued by influential Muslim clerics in Nigeria, warned their communities to avoid polio vaccination for it they said vaccine could make children sterile (Singhal, 2013).

The marginalized communities have little or no mass media exposure. However, sometimes marginalized mass suddenly reacts with rumors about OPV. They are illiterate and can't understand realty of decease. They thought OPV designed to control fertility in children. They believed polio campaigns were a continuation of coercive population control measures from the 1970s when the government forced people with 2 or more children to be sterilized (Coates et al. 2013, p.73). For instance, "We heard this rumor that this vaccine will affect some nerve in the children which will make them unable to produce children. We then thought that our children will become useless, nobody will marry them and our family will not be able to propagate. This is why we do not give the medicine", said Fatima Bai, a Muslim woman at a focus group discussion (UNICEF, 2003, p.15).

These type of comments slowly transmute into beliefs. It needs an opinion leader who can dispel misunderstanding and promote polio eradication campaign. The nature of eradication of disease involves routine work including a high degree of commitment of health workers, 
volunteers and mass media. Marketing will be considered in the health sector as successful when people demand for health services. Although success of health care facilities depends on two things, first mass media properly works to spread awareness among people about health care facilities, and second is the availabilities of health care facilities, for example mass media are inform, educate and motivate to people to adopt family welfare measures. To avail the services of family welfare people need a Community Health Center (CHC), Doctor's advice and medicine facilities. If there is no $\mathrm{CHC}$ then people are marginalized from health care facilities. Unavailability of health care facilities can drain all effort of development plan and mass media (Glashan, 2011, p.4).

\section{Television and Polio awareness campaign}

Mass media can create favourable environment for acceptance of health messages. Television creates public agenda and helps in the emergence of a propitious social climate, counter hostile propaganda, dispel rumors and clarify doubts and misunderstandings about health related issues. Being a dominant tool of information regarding health related issues; it can effectively raise awareness and motivate people towards achieving the desired goals. Television has enormous uncounted and scattered audiences. Large numbers of people acquire its information through a variety of television programs on community development, integration, agriculture, environment and health related issues. Mass media entertains people as well as makes them aware and educates on social development and health care issues. The prominent social scientist Rogers (1995) suggests that mass media can promote the diffusion and adoption of many technical and social innovations. The reach (penetration) and availability of mass media plays a very important role in spreading awareness about pulse polio, health and family welfare, HIV/AIDS prevention etc. Mass media programs in support of the polio eradication are expected to contribute as follows:

1. Carrying out advocacy among decision makers at different levels (global, national, state, regional and local)

2. Mobilize individual, groups, communities, opinion leaders, religious opinion leaders and government and NGOs to participate in polio eradication campaigns.

3. Inform public about poliovirus and dispel misconceptions and stigma and discrimination attached with leprosy.

\section{Importance of study}

As a developing country India has been struggling to overcome from its socio-economic backwardness and ill health due to illiteracy, unemployment. India has been successfully tackled and eliminated leprosy, pulse polio disease. This study aims at finding out the role played by mass media specially television in polio eradication in India. Goswami (2007, p.371) proclaims that television is most economical means of imparting information about health. It can effectively raise public awareness on polio eradication and create propitious environment for promoting public health. Hence, the study can be helpful to design prevention strategy to fight against severe disease such as pulse polio, HIV/AIDS, Tuberculosis etc.

\section{Research objectives}

To study which of the communication mediums are more popular in delivering health messages among Indian society?

To know the awareness level of people to participate in the final war against polio virus.

To know impact of Television's advertisement related to pulse polio campaign on people.

\section{Hypothesis}

As compared to other mediums Television played an important role in making people aware and 
mobilizing them enough to bring their children to polio booth for polio immunization.

\section{Research design and Method}

According to feasibility of research study, quantitative research design was chosen. Survey method was used to fulfill objectives of the research study. Furthermore, purposive and convenience sampling techniques were used for collection of the research data.

Data collection: Data for the research study is drawn from six villages, which lay under the Primary Health Center (PHC) of Sisendi of Mohanlal Ganj Block, Lucknow district. Scheduled Questionnaire tool was used to collect research data and 100 eligible parents who had up to 5 years aged children were administered from six villages of Sisendi PHC. While administering Scheduled questionnaire, head of the family (generally the male member) or in case of couple, husband or wife was taken as a respondent. SSPS 16.0 software was used for statistic of frequencies and M.S. Excel was used for graphical presentation of research report.

\section{FINDINGS AND INTERPRETATION}

The analytical framework based on systematic approach, two types of variables were considered namely independent variable (Mass media exposure) and dependant variable (awareness level of people on health issues and their participation in polio eradication). An attempt has been made in this chapter to synthesize and meaningfully analyze the major findings to look into the process of interaction of these variables.

\subsection{Means of mass communication}

\begin{tabular}{|l|l|c|c|c|c|c|}
\hline & & \multicolumn{4}{|c|}{ Which mass media do you use for acquiring } & \multirow{2}{*}{ information? } \\
\cline { 1 - 5 } & & \multicolumn{4}{|c|}{ Total } \\
\hline Sex & Female & 35 & 1 & 6 & 8 & 50 \\
& Male & 31 & 1 & 7 & 11 & 50 \\
\multirow{2}{*}{ Total } & & 66 & 2 & 13 & 19 & 100 \\
\hline
\end{tabular}

Table 1: Popular mass media for getting information about government policies and schemes.

The research study first examined mass media exposure of chosen peri-urban population. There were mix socio-economic demographic status of people. Their sources for livelihood were agriculture, labourer, teaching, own business government job and private service etc. Male member of family worked for livelihood and most of the females were housemaker. It was found that television is a popular medium for acquiring informatin in peri-urban society, and the percentage of male and female respondents is almost equal for using mass media as a means of getting information. 86 percent female respondents are depent on television for getting information while 84 percent male respondents are depend on television for getting information. 


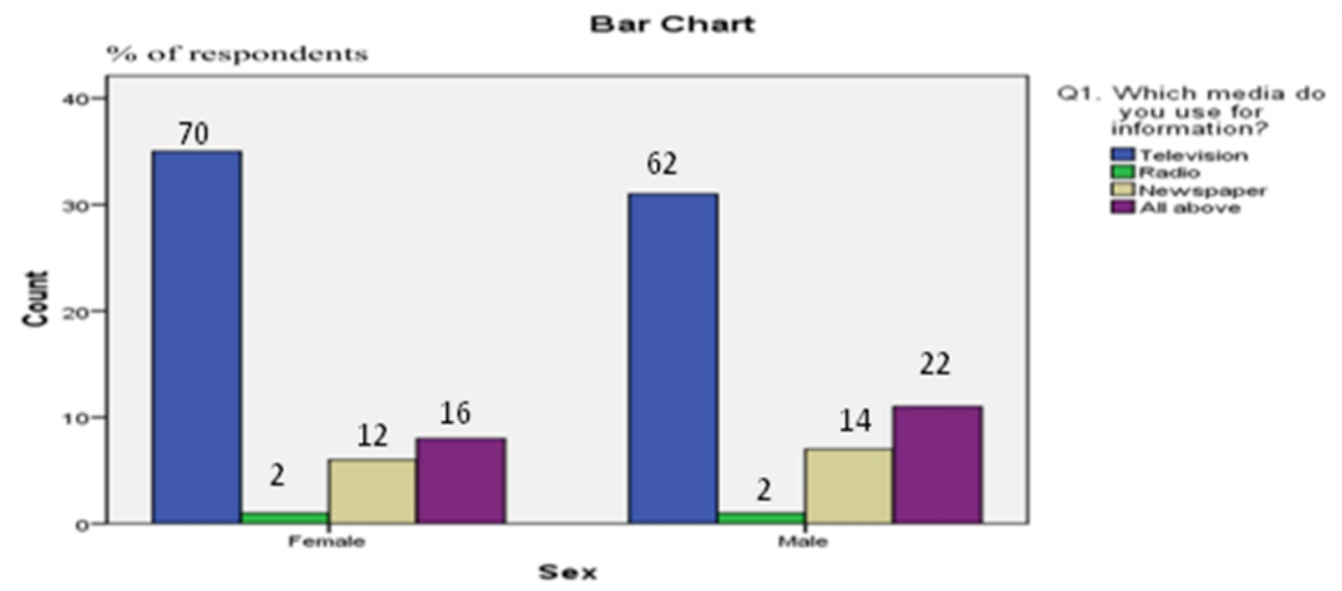

Figure 1: Mass media exposure of respondents

Figure 1 shows that 70 percent female and 62 percent male respondents, i.e, 66 percent of the respondents including male and female use television for getting information and entertaining themselves. 16 percent female and 22 male respondents, i.e, 19 percent of the administered respondents answered all above which included (television, radio and newspaper). It means that these 19 percent respondents are also getting information from television. Therefore, the study is indicated that total 85 percent $(66+19$ percent $)$ respondents use television as a primary source of information. It is interesting to know that demographic status of respondents are semi-urban but television is their main medium of mass communication for acquiring information instead of radio. Findings also suggest that 42 percent of people prefer radio for getting information.

\subsection{Awareness about pulse polio}

Figure 2 shows that 93 percent respondents have seen advertisement based on social issues at national television channel. This indicates that respondents have sufficient media penetration on social issues, and television is their main means of mass media for getting information about social issues. In the very next question, they were asked to mark disease which you saw on television. Figure 3 shows that 53 percent respondents watch advertisement of polio eradication and 13 percent respondents also give answer all above (Pulse polio, Tuberculosis, Cancer) it means that more than half of population, i.e., 66 percent of total population have heard about pulse polio through television.

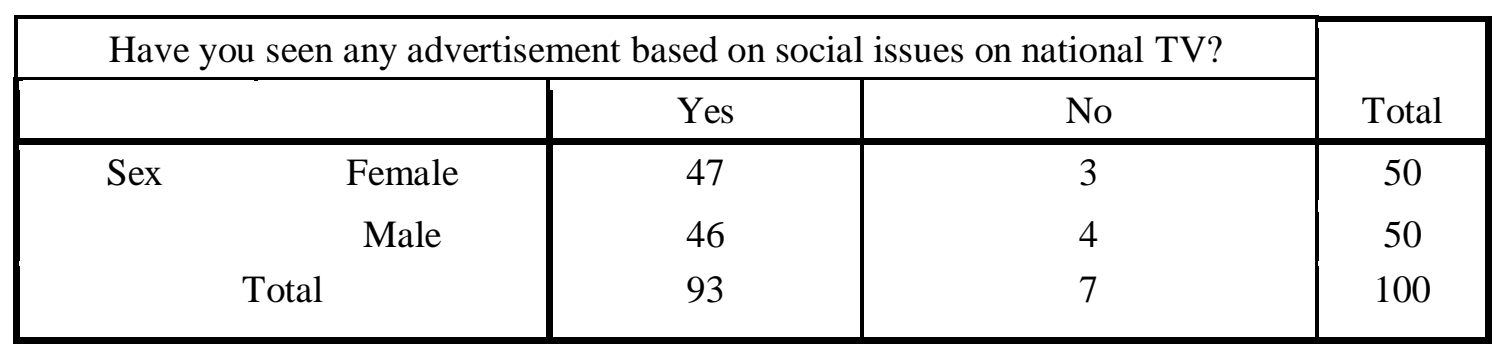

Table 2: Respondents who have seen social advertisements on television channels 


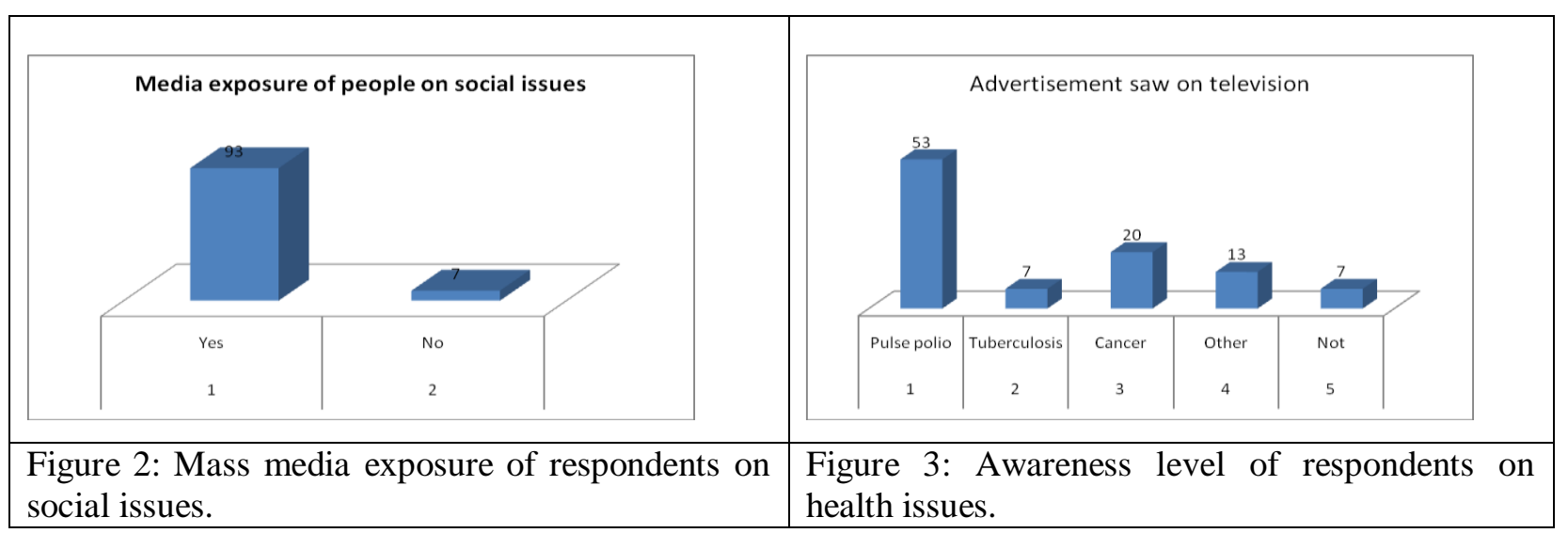

\subsection{Participation in polio eradication}

\begin{tabular}{|c|c|c|c|c|c|}
\hline & & \multicolumn{3}{|c|}{ Have your children taken polio drops? } & \multirow{2}{*}{ Total } \\
\hline & & 0 & Yes & No & 50 \\
Sex & Female & 0 & 50 & 0 & 50 \\
& Male & 2 & 46 & 2 & 100 \\
\hline
\end{tabular}

Table 3: Respondents whose children have taken polio drops

On applying correlation between mass media exposure and awareness level of people pertaining to health issues, it is found that a positive relation exists between respondents' mass media exposure and behavior chance towards participation in polio eradication campaign. It implies that respondents' increasing mass media exposure leads increasing of their participation in polio eradication. The study reveals that 100 percent female respondents have accepted that their children regularly takes polio drops during polio eradication campaign while 92 percent of male respondents have responded positively toward participation in polio eradication campaign. It is clear that 100 percent female and 92 percent male respondents have participated in polio eradication.

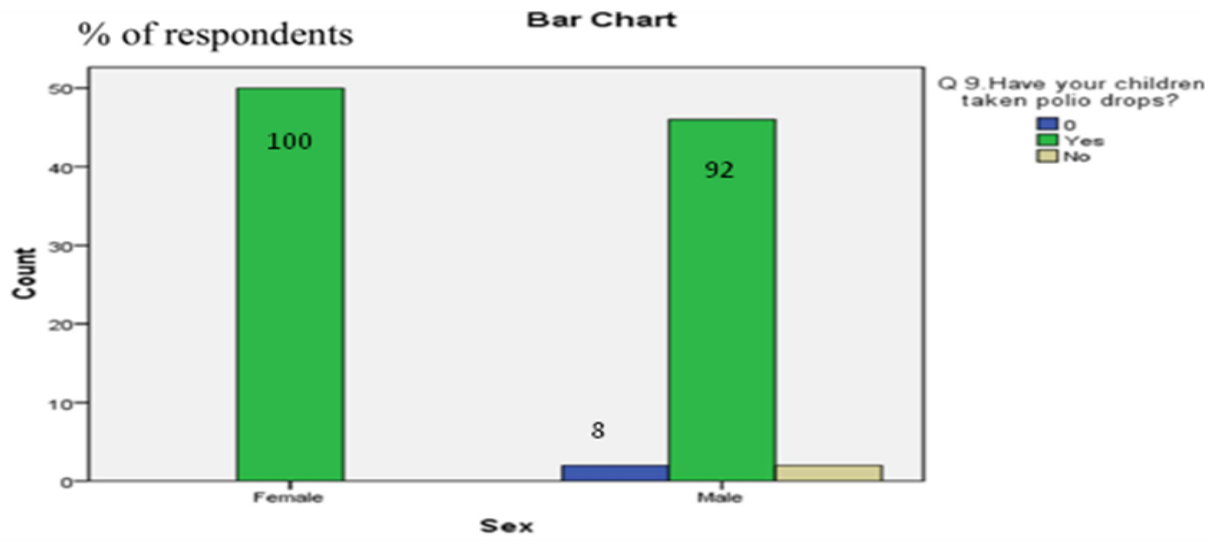

Figure 4: Shows participation of people in Polio immunization 
It is clear from Figure 1, 2 \& 3 that television is the prime source of mass communication for spreading awareness about health related issues. Most of people saw advertisement of Pulse Polio on television channels. Figure 4 shows that 100 percent female and 92 percent male, i.e., 96 percent of respondents have participated in Pulse Polio eradication. It was found that those people who were exposed towards mass media messages of Pulse Polio had positive attitude towards polio immunization and more frequently participated in Polio immunization.

Hence, $H_{l}$ "As compared to other medium television played an important role in making people aware and mobilizing them enough to bring their children to polio booth for polio immunization" is true. It means that television has informed, educated and mobilized masses to adopt positive health behavior. It has also broadcasted polio eradication messages and dispelled rumours attached to polio disease and vaccine among urban as well as rural population. In turn, the masses undoubtedly brought their children to the polio booth for immunization.

\section{DISCUSSION}

This study is an attempt to find out answers of few basic questions related to health communication and polio eradication. The sample ground chosen for this study was urban and semi-urban areas of Lucknow, Uttar Pradesh. The hypothesis that the researcher conjured is "As compared to other mediums television played an important role in making people aware and mobilizing them enough to bring their children to polio booth for polio immunization" and as per the data stated above, it is found to be true. Going hand in hand with popular belief, television has turned out to be the most popular and effective mass medium for health communication (Flora, Maibach \& Maccoby, 1989). The research findings (refer to question No.1 in the Findings section), indicated that television was most popular and successful medium for spreading awareness in semi-urban areas of Lucknow district. There was positive relation between mass media exposure of people and their participation towards polio eradication. The study revealed that mass media exposure of people was the predictor of awareness about polio eradication in semi-urban society (Yadav et al., 2011. p.715). The study resulted that 85 percent of total respondents used television as a mass media tool for acquiring information (Singh, Mishra, 2013, p.125) but their participation in polio eradication told more promising and successful story.

When asked, have you seen advertisements pertaining to social awareness? It was found that 93 percent of the respondents (both male and female) claimed that they had seen such advertisements on television channels. The next question that followed was - on which social issues have you seen the most advertisements? Four options were given to the respondents namely - Polio, TB, Cancer and other. 53 percent of the respondents said that they were aware about polio and had seen pulse polio advertisements on TV (Osowole \& Obute, 2005) while TB and Cancer also raked up high numbers. Similar findings were found elsewhere (Nawathe, Gawande \& Dethe, 2007). The study indicated that 94 percent respondent claimed they came to the polio booths after seeing ads on television, which was endorsed by celebrities like Amitabh Bachchan, Shahrukh Khan, Sachin Tendulkar and Jaya Bachchan. The third and final question touched on whether these advertisements were able to inspire people into getting their children to take polio drops. In this regard, 96 percent of the respondents answered 'yes'. It is found that 96 percent respondents exposed to polio television ads reported taking their children to the polio booth for vaccination (Obregón et al., 2009). The majority of respondents remembered that bollywood actor Amitabh Bachchan was 
endorsing pulse polio, as this was the first thing that came to their mind when they heard about pulse polio. Therefore, endorsement of celebrities played very important role in communicating about polio immunization (Bansal \& Jain, 2012, p.375)

Thus, it is concluded that television is most popular and effective medium for spreading information among semi-urban community. Mass media, especially television because of their wide reach, strong appeal and cost effectiveness have been major mass media tools for spreading awareness among semi-urban community. It can effectively promote health intervention and disease prevention. It is also concluded that there is positive relation between mass media exposure of people and their participation towards polio eradication. Television effectively creates awareness, educates and mobilizes people to participate in polio eradication. Television, because of its Audio-Visual and entertaining feature is most popular medium in rural community. The people living in rural areas use television as a mass media tool for entertainment as well as acquiring information like political news, health, education etc. While examining the role of celebrities in polio eradication campaign, it is found that the celebrities have played very important role in creating awareness and influence people's perception to participate in polio eradication. For instance, Amitabh Bachchan was regularly seen informing, influencing, motivating and mobilizing parents to bring their children on polio booth for immunization since 2002. He was continuously advising and persuading parents to ensure "do boond zindagi ki" (two drops of polio vaccine) for every child every time.

\section{CONCLUSION}

Thus, the study is concluded that television, as a mass medium is a very effective tool for health communication. It can also be argued that it has played a very pivotal role in making India polio- free. It must also be kept in mind that these results need to be build upon and such a study should be conducted in other regions across India to definitively conclude that television is the best mass medium for health communication.

$===============================$
SANTOSH K. GAUTAM, Research Scholar,
School of Media and Communication Studies
Doon University, Dehradun, Uttarakhand, India.

\section{REFERENCE}

Bansal, H. \& Jain, A. (2013). Pulse Polio Abhiyan: The Most Effective Social Cause Marketing by the Government of India (p.375). International Conference on Sustainable Business Growth in Turbulent Times: Opportunities \& Challenges. Ambala: Galaxy Global Institute. Retrieved from: http://www.gjust.ac.in/department/ biodata/HSB/harbhajan_Bansal_24.09.2014.pdf

Bhattacharjee J., Gupta R. S., Jain D. C., Devadethan \& Datta

K.K. (1997). Evaluation of Pulse Polio and Routine Immunisation Coverage : Alwar District, Rajasthan. The Indian Journal of Pediatrics, 64, 66.

Coates, E. A., Waisbord, S., Awale, J., Solomon, R. \& Dey, R. (2013). Successful polio eradication in Uttar Pradesh, India: the pivotal contribution of the Social Mobilization Network, an NGO/UNICEF collaboration. Global health: Science and Practice, 1(1), 68-83. Retrieved from: http://www.ghspjournal.org/content /1/1/68.full

Flora, J. A., Maibach, E. W. \& Maccoby, N. (1989). The Role of Media across Four Levels of Health Promotion Intervention. Annual Review of Public Health, 10, 181-201.

Glashan, G. (2011). Designing Communication strategies for Polio Eradication Campaign: A Case stud. Global Media Journal, Vol.2(2), Indian Edition/ISSN 2249-5835

Goswami, R. (2007). Role of marketing in polio eradication, pp.371386, IIMK, Available from: http://dspace.iimk.ac.in/bitstream/handle/2259/658/371386.pdf? sequence $=1$ 
John T. J. (2006). Polio Eradication: A National Commission Required, p.5230, Published by Economic and Political Weekly, Available from: http://www.jstor.org/stable/4419051

John, T. J. (1984). 'Poliomyelitis in India: Prospects and Problems of Control', Reviews in Infectious Diseases, 6, S438-S441

Kulkarni, M. M. (1992). Universal Immunisation Programme in India: Issues of Sustainability, Information, Education and Communication, pp.1434-1435 Published by Economic and Political Weekly, Vol. 27( 27), Available from: http://www.jstor.org/stable/4398590

Nawathe, A., Gawande, R., Dethe, S. (2007). Impact of Advertising on Children's health, International marketing Conference on Marketing and Society, 8-10 April 2007, IIMK, Available from: http://dspace.iimk.ac.in/bitstream/2259/356/1/303-311.pdf

Obregón, R., Chitnis, K., Morry, C., Feek, W., Bates, J., Galway, M., Ogden, E. (2009). Achieving polio eradication: a review of health communication evidence and lessons learned in India and Pakistan, Available from: http://www.who.int/bulletin/volumes/87/8/08060863/en/

Osowole O.S., Obute J.A. (2005), Parents' Awareness and perception of the polio Eradication programme in Gombe local Government area, Gombe state, Available from: http://demoscope.ru/weekly/knigi/tours_2005/papers/iussp2005s5081 0.pdf

Rogers, E. M. (1995). Diffusion of innovations, fourth edition, Communication campaign, p. 344, The Free Press, New York.

Sachffer, T. C. (January 2012). Polio eradication in India: getting to the verge of victory and beyond, Center for Strategic \& International Studies, pp. 1-18, Available from: https://csisprod.s3.amazonaws.com/s3fspublic/legacy_files/files/publication/120117_Schaffer_PolioIndia_We b.pdf

Schiavo, R,. (2007). Health communication, From Theory to practice, San Francisco, Jossey-Bass.

Singh D., Mishra O.P., (2013). Availability and Use of Information Sources by the Rural Families of Balia District of Uttar Pradesh, p.125, Journal of Global Communication, Vol.6(2), DOI: 10.5958/j.0978-2442.6.2.019 UNAIDS-2012, AIDS info.
Singhal, A. (2013). Adoptive Macro and Micro Communication Strategies to Eradicate polio in India: Social Mobalisation, Opinion leadership and Interpersonal influence at unprecedented scale, p.7, International Journal of Communication and Social Research, Vol 1(1), Available from: http://utminers.utep.edu/asinghal/SinghalIndia's\%20Polio\%20Communication\%20Story-2013-

IJCSR_CUK_vol-I_no-1.pdf

UNICEF (2003). A critical leap to polio eradication in India, pp. 184, Available from: www.unicef.org/rosa/critical.pdf

UNICEF (2012), Online Report- India polio fact sheet, Available from:

www.unicef.org/india/Polio_India_Fact_Sheet13January2012.doc

Weiss, W. M., Rahman M. H., Solomon, R., Singh, V., Ward, D. (2011). Outcomes of polio eradication activities in Uttar Pradesh, India: the Social Mobilization Network (SM Net) and Core Group Polio Project (CGPP), pp.2-4, BioMed Central Ltd., Infectious diseases 2011, Available from: http://www.biomedcentral.com/1471$2334 / 11 / 117$

Yadav B. S, Makwana R. N., Vadera N. B., Dhanuk M. K., Gandha M. K. (2011). Awareness about HIV/AIDS among Rural youth in India: A Community based cross sectional study, p.715, J Infect Dev Ctries 2011. 5(10):711-716.

Yzer, M. (2009).The Integrative Model of Behavioural Prediction as a Tool for Designing Health Messages, Health Communication Message Design: Theory and Practice, pp.30-31, Sage publication, New Delhi. 